\title{
Pengaruh Motivasi, Budaya, dan Sikap Konsumen Terhadap Keputusan Pembelian Produk Indomie
}

\author{
Keren dan Sulistiono \\ Program Studi Manajemen, Sekolah Tinggi Ilmu Ekonomi Kesatuan \\ Bogor, Indonesia \\ E-Mail: angga.sulistiono@stiekesatuan.ac.id
}

Submitted:

DESEMBER 2019

Accepted:

DESEMBER 2019

\begin{abstract}
Consumption of instant noodle products in Indonesia is quite high. Especially the Indomie instant noodle which is the market leader in the Indonesian instant noodle product market. In purchasing products, consumers are influenced by three factors, namely motivation, culture, and consumer attitudes. This research is a survey research with data collection method through interviews using a questionnaire instrument to 100 respondents in the Bogor city. Based on the analysis of the data obtained, it is known that of the three variables studied, Consumer Attitude is the most influential variable on the Purchase Decision of Indomie brand instant noodle products because it has the greatest beta value among the other variables. From the partial test results ( $t$ and $F$ test) it can be obtained that the three exogeneus variables (Consumer Motivation, Culture, and Consumer Attitudes) have the same strong and positive influence simultaneously on the Purchase Decision of Indomie brand instant noodle products.
\end{abstract}

Keywords : culture, motivation, attitude, purchase decision

\section{PENDAHULUAN}

Dalam melakukan pembelian suatu produk, banyak sekali faktor faktor yang dipertimbangkan oleh para konsumen untuk membuat keputusan. Di samping keadaan perekonomian dari masing - masing konsumen. Terkadang hal tersebut juga menjadi pertimbangan bagi produsen dan perusahaan untuk mengembangkan produk mereka. Tentu produk yang dibuat oleh produsen haruslah didedikasikan sepenuhnya untuk kebutuhan para konsumen dan diusahakan agar dapat sesuai dengan harapan konsumen. Mengetahui hal ini, maka para pemasar perlu memahami secara mendalam faktor - faktor apa sajakah yang mempengaruhi keputusan pembelian konsumen.

Terkadang sering kita temukan di pasar, sebuah produk yang begitu marak dikonsumsi oleh konsumen, di samping produk - produk lainnya. Hal tersebut tentunya akan meningkatkan penjualan pada perusahaan produk yang bersangkutan. Jika diperhatikan, produk yang dapat menguasai pasar seacam itu tidak melulu merupakan produk yang unik atau beraneka ragam, melainkan produk yang serupa (homogen). Produk semacam itu seringkali lebih marak diokonsumsi, mampu menarik hati pelanggan, dan mampu memenangkan persaingan di pasar. Sebagai contoh, di Indonesia, marak sekali konsumsi produk mie instan. Memang, mie instan merupakan produk makanan cepat saji dengan segala kelebihan - kelebihannya, yakni cara pembuatannya praktis dan memiliki banyak varian rasa yang dapat dipilih sesuai selera. Selain itu, mie instan dapat menjadi makanan yang siap di makan kapan saja, baik itu pagi,siang, atau malam sebagai pengganti menu makanan yang lain. Maka, tak heran, produk mie instan sangat marak di konsumsi di Indonesia. Produk mie instan sudah memiliki banyak sekali konsumen yang loyal dari berbagai kalangan, terutama kalangan muda mudi yang meliputi pelajar hingga mahasiswa. Tak lupa, produk mie instan juga harganya sangat terjangkau sehingga tak

\section{JIMKES}

Jurnal Ilmiah Manajemen Kesatuan Vol. 7 No. 3, 2019 pp. $319-32$ IBI Kesatuan ISSN $2337-7860$ 
Consumers'

Purchasing

Decision

heran banyak sekali konsumen yang lebih memilih mie instan daripada makanan utama lainnya.

Indomie sudah menjadi merek lokal produk mie instan yang paling terkenal, bahkan sudah terkenal di negara - negara lain, sekaligus merupakan market leader bagi produk produk mie instan merek lainnya. Indomie sudah dapat mencetak keuntungan yang sangat besar sebagai produk lokal dan patut menjadi kebanggaan bagi dunia perekonomian di Indonesia.

Berdasarkan data yang diperoleh pada tahun 2016, PT. Indofood Sukses Makmur masih menjadi penguasa pasar mie instan di Indonesia. Berdasarkan data Bloomberg (2016), Indofood Sukses Makmur menguasai pangsa pasar sekitar 70,7 persen dengan produk mie instan. Meskipun Mie Sedap (produksi Wingsfood) mulai menarik para kosumen yang gemar mengkonsumsi mi instan lokal, namun pangsa pasarnya masih jauh di bawah mie instan merek Indomie, yang diproduksi oleh PT. Indofood Sukses Makmur.

Menurut para ahli mengenai perilaku konsumen, semuanya menyetujui dan mengemukakan adanya keterlibatan beberapa faktor-faktor yang mempengaruhi konsumen dalam pengambilan keputusan ketika para konsumen hendak membeli suatu produk. Seperti yang dikemukakan oleh Sumarwan (2011), proses keputusan konsumen dipengaruhi oleh tiga faktor utama, yakni strategi pemasaran, perbedaan individu, dan faktor lingkungan. Berdasarkan hal tersebut, yang ingin dibahas oleh penulis dalam penelitian ini adalah faktor dalam hal perbedaan individu dan faktor lingkungan sebagai faktor yang mempengaruhi pengambilan keputusan konsumen.

Sumarwan (2011) mengemukakan bahwa faktor - faktor karakteristik individu yang dapat mempengaruhi pengambilan keutusan konsumen, di antaranya adalah agama, kebutuhan dan motivasi, kepribadian, pengolahan informasi dan persepsi, proses belajar, pengetahuan, dan sikap konsumen. Sedangkan,faktor lingkungan konsumen meliputi budaya, karakteristik demografi,sosial, dan ekonomi, keluarga, kelompok acuan, lingkungan dan situasi konsumen, serta teknologi.

Mie instan merek Indomie yang diproduksi oleh PT. Indofood Sukses Makmur tetap mampu menguasai pasar domestik, meski pesaingnya, yakni Mie Sedap yang diproduksi oleh Wingsfood juga mulai menarik perhatian para konsumen. Berkaitan dengan hal ini, penulis melihat adanya penyebab khusus yang menjadi alasan mengapa para konsumen lebih memilih mie instan merek Indomie ketimbang pesaingya. Penulis melihat adanya faktor motivasi dari dalam diri konsumen, yang membuat para konsumen lebih memilih produk mie instan merek Indomie dibanding pesaingnya. Selain itu, faktor - faktor lain di samping motivasi juga turut mempengaruhi konsumen dalam memilih mie instan merek Indomie.

Adapun permasalahan dari penelitian ini adalah : Apakah motivasi konsumen, budaya, dan sikap konsumen secara bersama - sama berpengaruh terhadap keputusan pembelian produk mie instan Indomie? Seberapa besar motivasi konsumen berpengaruh terhadap keputusan pembelian pada produk mie instan Indomie? dan Seberapa besar budaya berpengaruh terhadap keputusan pembelian produk mie instan Indomie? Seberapa besar sikap konsumen berpengaruh terhadap keputusan pembelian produk mie instan Indomie?

\section{TINJAUAN PUSTAKA}

\section{Keputusan Pembelian}

Pengambilan keputusan dalam pembelian didefinisikan oleh Machfoedz (2010) sebagai suatu proses menilai dan memilih dari berbagai alternatif (produk) yang tersedia sesuai dengan kepentingan konsumen, untuk menetapkan suatu pilihan yang dianggap paling menguntungkan. Kotler dan Amstrong (2008) menjelaskan keputusan pembelian sebagai suatu tahap proses keputusan di mana konsumen melakukan pembelian produk.

\section{Motivasi Konsumen}

Sangadji dan Sopiah (2013), menjelaskan bahwa kata motivasi berasal dari bahasa Latin movere yang artinya 'menggerakkan' (halaman 154). Motivasi adalah dorongan dari yang muncul dari dalam diri atau dari luar diri (lingkungan) yang menjadi faktor penggerak 
kearah tujuan yang ingin dicapai. Terkait dengan konsumen, motivasi bisa diartikan sebagai suatu dorongan yang menggerakan konsumen untuk memutuskan bergerak kearah pencapaian tujuan,yaitu memenuhi berbagai macam kebutuhan dan keinginan (halaman 155).

\section{Budaya}

Menurut Supranto dan Limakrisna (2011), budaya (culture) adalah keseluruhan yang kompleks (complex whole) meliputi pengetahuan, kepercayaan, seni, hukum, moral, kebiasaan dan setiap kemampuan dan kebiasaan yang diperoleh oleh setiap orang sebagai anggota masyarakat. Budaya bersifat tidak statis, karena dapat berubah dari waktu ke waktu (halaman 21). Menurut Sumarwan (2011), budaya adalah segala nilai, pemikiran, simbol, yang mempengaruhi perilaku, sikap, kepercayaan, dan kebiasaan seorang masyarakat. Budaya tidak hanya yang bersifat abstrak seperti nilai, pemikiran dan kepercayaan. Budaya bisa berbentuk objek material. Rumah, kendaraan, peralatan elektronik, dan pakaian adalah contoh - contoh produk yang yang bisa dianggap sebagai budaya suatu masyarakat. Budaya akan mempengaruhi sikap, presepsi, dan perilaku konsumen. (halaman 13)

\section{Sikap Konsumen}

Menurut Sumarwan (2011), sikap (attitudes) konsumen adalah faktor penting yang akan mempengaruhi keputusan konsumen. Konsep sikap sangat terkait dengan konsep kepercayaan (belief) dan perilaku (behavior). Sikap merupakan ungkapan perasaan konsumen tentang suatu objek apakah disukai atau tidak, dan sikap juga bisa menggambarkan kepercayaan konsumen terhadap berbagai atribut dan manfaat dari objek tersebut. Kepercayaan konsumen adalah pengetahuan konsumen mengenai suatu objek, atributnya, dan manfaatnya . (halaman 12)

\section{METODOLOGI PENELITIAN}

Penelitian ini dilakukan di STIE Kesatuan Bogor dimana para mahasiswa /mahasiswi STIE Kesatuan Bogor yang mengkonsumsi mie instan merek Indomie sebagai populasinya. Penelitian dilaksanakan pada bulan Mei hingga Juni 2018. Untuk menentukan sampel penelitian digunakan perhitungan maupun acuan tabel yang dikembangkan para ahli. Secara umum, untuk penelitian korelasional jumlah sampel minimal untuk memperoleh hasil yang baik adalah 30, sedangkan dalam penelitian eksperimen jumlah sampel minimum 15 dari masing-masing kelompok dan untuk penelitian survei jumlah sampel minimum adalah 100. Dalam penentuan pengambilan jumlah responden (sampel) dilakukan teknik purposive sampling, yaitu teknik pengambilan sampel dengan memilih anggota populasi yang dianggap paling tepat sebagai sumber informasi yang akurat. Analisis data penelitian yang dilakukan penulis adalah dengan cara pendekatan kuantitatif, yaitu teknik analisis data yang berkenaan dengan perhitungan untuk menjawab rumusan masalah dan pengujian hipotesis.

\section{HASIL DAN PEMBAHASAN \\ Karakteristik Responden}

Jumlah responden yang menjadi sampel dalam penelitian ini berjumlah 100 orang yang berasal dari para konsumen produk mi instan Indomie. Data mengenai identitas responden berdasarkan pada jenis kelamin, usia, pendidkan terakhir, pekerjaan, pendapatan, dan status pernikahan. (Tabel 1)

\section{Analisis Asosiatif Variabel Eksogen dan Variabel Endogen}

Berdasarkan hasil uji reliabilitas, nilai cronbach's alpha untuk variabel Keptusan Pembelian sebesar 0,753 dan nilai cronbach lebih besar dari 0,60 maka dapat dinyatakan reliabel. Begitu pula dengan variabel Motivasi Konsumen sebesar 0,810; variabel Budaya sebesar 0,703 ; dan variabel Sikap Konsumen sebesar 0,901. Semuanya memiliki nilai cronbach lebih besar dari 0,60 maka dapat dinyatakan reliabel. 
Consumers'

Purchasing

Decision
Tabel 1 Distribusi Frekuensi Responden Penelitian

\begin{tabular}{|c|c|c|c|c|}
\hline \multirow[t]{6}{*}{$\begin{array}{l}\text { Purchasing } \\
\text { Decision }\end{array}$} & \multicolumn{2}{|r|}{ Karakteristik } & \multirow{2}{*}{$\begin{array}{c}\begin{array}{c}\text { Jumlah } \\
\text { Responden }\end{array} \\
39\end{array}$} & Prosentase \\
\hline & Jenis Kelamin & Laki-laki & & 39.0 \\
\hline & & Wanita & 61 & 61.0 \\
\hline & Usia & 17-25 tahun & 91 & 91.0 \\
\hline & & $26-35$ tahun & 7 & 7.0 \\
\hline & & $>46$ tahun & 2 & 2.0 \\
\hline \multirow{14}{*}{322} & Pendidikan & SMP & 1 & 1.0 \\
\hline & Terakhir & SMA / SMK & 82 & 82.0 \\
\hline & & D3 & 5 & 5.0 \\
\hline & & Sarjana & 12 & 12.0 \\
\hline & Pekerjaan & Pelajar/Mahasiswa & 83 & 83.0 \\
\hline & & Karyawan & 13 & 13.0 \\
\hline & & PNS & 1 & 1.0 \\
\hline & & Wiraswasta & 3 & 3.0 \\
\hline & Pendapatan & $<$ Rp. 3.000.000,- & 83 & 83.0 \\
\hline & & Rp. 3.000.000,- - Rp. 4.000.000,- & 13 & 13.0 \\
\hline & & Rp. 5.000.000,- - Rp. 10.000.000,- & 2 & 2.0 \\
\hline & & Rp. 10.000.000,- & 2 & 2.0 \\
\hline & Status Pernikahan & Sudah menikah & 9 & 9.0 \\
\hline & & Belum menikah & 91 & 91.0 \\
\hline
\end{tabular}

Tabel 2 Hasil Uji Korelasi Variabel Motivasi, Budaya dan Sikap Konsumen dan Keputusan Pembelian Produk Indomie

\begin{tabular}{lcc}
\hline \multicolumn{1}{c}{ Variabel } & \multicolumn{2}{c}{ Word ofMouth } \\
& Korelasi Pearson & Signifikansi \\
\hline Motivasi Konsumen & 0.692 & 0,000 \\
Budaya & 0.829 & 0.000 \\
Sikap Konsumen & 0,877 & 0,000 \\
\hline
\end{tabular}

Sumber: Data Primer Diolah

Tabel 3 Hasil Analisis Regresi Berganda Variabel Motivasi, Budaya dan Sikap Konsumen dan Keputusan Pembelian Produk Indomie

\begin{tabular}{lccc}
\hline \multicolumn{1}{c}{ Keterangan } & Koefisien & $\mathrm{t}_{\text {hitung }}$ & Signifikansi \\
\hline (Konstanta) & & 1.290 & 0.200 \\
Motivasi Konsumen & & 3.582 & 0.001 \\
Budaya & & 1.363 & 0.176 \\
Sikap Konsumen & & 5.732 & 0.000 \\
R & 0.822 & & \\
R Square & 0.675 & & \\
Adjusted R Square & 0.665 & & 0.000 \\
$F_{\text {hitung }}$ & 66.520 & & \\
Y= Keputusan Pembelian & & & \\
\hline
\end{tabular}

Sumber: Data Primer Diolah

Dari hasil uji normalitas diperoleh data variabel X1 (Motivasi Konsumen) dengan rasio skewness dan rasio kurtosis $-0,579 ; 0,631$ yang dimana diantara -2 dan +2 yang dinyatakan normal. Variabel X2 (Budaya) dengan rasio skewness dan rasio kurtosis -0,949; 2,351 yang dimana diantara -2 dan +2 yang dinyatakan normal. Variabel X3 (Sikap Konsumen) dengan rasio skewness dan rasio kurtosis $-1,157 ; 2,438$ yang dimana diantara -2 dan +2 yang dinyatakan normal. Variabel $Y$ (Keputusan Pembelian) dengan rasio skewness dan rasio kurtosis $-1,086 ; 2.618$ yang dimana diantara -2 dan +2 yang dinyatakan normal. 
Dari hasil uji multikolineritas, dapat dilihat nilai tolerance untuk Motivasi Konsumen, Budaya dan Sikap Konsumen adalah 0,466, 0,276 dan 0,456. Nilai tolerance di atas 0.1 sehingga dapat disimpulkan bahwa tidak terjadi multikolinearitas antar variabel bebas. Hasil pengujian variabel bebas VIF untuk Motivasi Konsumen adalah 2,148, Budaya adalah 3,629, dan Sikap Konsumen adalah 2,194. Dari hasil pengujian tersebut dapat disimpulkan bahwa tidak terjadi multikolinearitas antar variabel bebas. Dengan demikian uji asumsi klasik tidak adanya multikolinearitas dapat terpenuhi.

Berdasarkan hasil uji heteroskedastisitas, diketahui bahwa variabel independen $\mathrm{X}_{1}$ (Motivasi Konsumen) dan $\mathrm{X}_{3}$ (Sikap Konsumen) mempunyai nilai Sig. $<0,05$ atau di bawah $5 \%$, sedangkan variabel $X_{2}$ (Budaya) mempunyai nilai Sig. $>0,05$ atau di atas $5 \%$. Maka dapat ditarik kesimpulan bahwa terjadi heteroskedastisitas pada variabel X1 (Motivasi Konsumen) dan X3 (Sikap Konsumen), namun tidak terjadi heteroskedastisitas pada variabel X2 (Budaya).

Berdasarkan persamaan regresi, dapat diperoleh rumus seperti di bawah ini: $\hat{Y}=1,625+0,379 X_{1}+0,215 X_{2}+0,713 X_{3}+$ error

Berdasarkan persamaan regresi tersebut; jika :

a. $\mathrm{X} 1=\mathrm{X} 2=\mathrm{X} 3=0$, maka $\mathrm{Y}$ akan bernilai sebesar konstantanya yaitu 1,625.

b. Jika X1 (Motivasi Konsumen) naik 1 (satu) satuan maka Y (Keputusan Pembelian) akan naik sebesar 0,379 apabila variabel lain dianggap konstan.

c. Jika X2 (Budaya) naik 1 (satu) satuan maka Y (Keputusan Pembelian) akan naik sebesar 0,215 apabila variabel lain dianggap konstan.

d. Jika X3 (Sikap Konsumen) naik 1 (satu) satuan maka Y (Keputusan Pembelian) akan naik sebesar 0,713 apabila variabel lain dianggap konstan.

Berdasarkan analisis korelasi dan koefisien determinasi, dapat dijelaskan bahwa hubungan atau korelasi berganda pada seluruh variabel (Motivasi Konsumen, Budaya dan Sikap Konsumen) memiliki kekuatan hubungan yang sangat kuat. Hal ini berdasarkan nilai koefisien korelasi berganda sebesar 0,822. Perolehan nilai $r$-square sebesar 0,675 dapat dijelaskan bahwa variabel Motivasi Konsumen, Budaya dan Sikap Konsumen mampu mempengaruhi atau menjelaskan keragaman (variabilitas) nilai dari keputusan pembelian sebesar $67,5 \%$ sedangkan sisanya sebesar $32,5 \%$ dipengaruhi atau dijelaskan oleh variabel lain yang tidak diteliti.

Berdasarkan hasil uji $\mathrm{F}$, diperoleh nilai $\mathrm{F}$ hitung sebesarnya 66,520 dan $\mathrm{F}$ tabel sebesar 2,70 dengan demikian maka $\mathrm{F}$ hitung lebih besar dari $\mathrm{F}$ tabel atau $(66,520<2,70)$. Dari hasil uji $\mathrm{T}$, diperoleh nilai $\mathrm{T}$ hitung untuk variabel motivasi konsumen adalah sebesar 3,582 ; variabel budaya sebesar 1,363 dan variabel sikap konsumen adalah sebesar 5,732 di mana semua nilainya lebih besar dari t-tabel $(\mathrm{df}=\mathrm{n}-\mathrm{k}-1=100-3-1, \alpha=5 \%=1,66)$. Maka, semua variabel bebas dapata dikatakan berpengaruh positif terhadap variabel independennya.

\section{PENUTUP}

Berdasarkan hasil uraian penelitian, maka dapat ditarik kesimpulan sebagai berikut:

1. Motivasi konsumen, budaya, dan sikap konsumen secara bersama - sama berpengaruh positif dan signifikan terhadap keputusan pembelian produk mi instan merek Indomie. .

2. Motivasi konsumen berpengaruh positif terhadap keputusan pembelian produk mi instan merek.

3. Budaya berpengaruh positif terhadap keputusan pembelian produk mi instan merek Indomie.

4. Sikap konsumen berpengaruh positif dan signifikan terhadap keputusan pembelian produk mi instan merek Indomie.
Consumers'

Purchasing

Decision 
Consumers'

Purchasing

Decision

\section{DAFTAR PUSTAKA}

Alma, Bunchari. 2014. Manajemen Pemasaran dan Pemasaran Jasa, Alfabeta, Bandung. Chernev, Alexander. 2018. Strategic Marketing Management, $9^{\text {th }}$ Edition. Chicago Cerebellum Press.

Dharmmesta, Basu Swastha, Handoko, T. Hani. 2012. Manajemen Pemasaran Analisis Perilaku Konsumen, Edisi Pertama. Yogyakarta : BPFE

Juliardi, Budi. 2014. Ilmu Sosial Budaya Dasar. Bandung : Alvabeta, CV.

Kanuk \& Schiffman. 2010. Consumer Behavior Tenth Edition. New York : Pearson Education.

Kotler, Phillip; Amstrong, Garry. 2008. Prinsip - Prinsip Pemasaran, Edisi 12. Jakarta: Erlangga.

Kotler, Phillip dan Kevin Lane Keller. 2012. Marketing Management. Edisi Ke 14. Jakarta: Erlangga

Machfoedz, Mahmud. 2010. Komunikasi Pemasaran Modern. Yogyakarta : Cakra Ilmu.

Mooij, Marieke De. 2011. Consumer Behavior and Culture : Consequences for Global Marketing and Advertising, $2^{\text {nd }}$ Edition. USA : Sage Publications, Inc.

Peter, J Paul \& Jerry C. Olson. 2013. Perilaku Konsumen dan Strategi Pemasaran, Edisi 9, buku 1. Jakarta: Salemba Empat.

Sangadji, Etta Mamang \& Sopiah. 2013. Perilaku Konsumen : Pendekatan Praktis. Yogyakarta : CV Andi Offset.

Sumarwan, Ujang. 2011. Perilaku Konsumen : Teori dan Penerapannya Dalam Pemasaran, Edisi Kedua. Bogor : Ghalia Indonesia.

Supranto, J \& Nandan Limakrisna. 2011. Perilaku Konsumen \& Strategi Pemasaran Untuk Memenangkan Pesaingan Bisnis. Bogor:Mitra Wacana Media.

Suryani, Tatik. 2008. Perilaku Konsumen : Implikasi Pada Strategi Pemasaran. Yogyakarta : Graha Ilmu.

Swasta Basu, dan T. Hani Handoko. 2008. Manajemen Pemasaran, Analisa Perilaku Konsumen, Edisi Pertama, Cetakan Keempat. Yogyakarta : BPFE.

Albarracin, Dolores dan Sharon Shavitt. (2017). Attitudes and Attitude Change. Annual Reviews of Physicology Vol 69, pp : $299-327$.

Djatikusuma, E. (2014). Analisis Faktor - Faktor Yang Mempengaruhi Keputusan Pembelian Konsumen Pada Minuman Berisotonik Pocari Sweat. Jurnal STIE MDP.

Fernandez, Raquel. (2010). Does Culture Matter, Handbook of Social Economics, Vol 1A, North Holland.

Giantara, Mariani Shoshana, Jesslyn Santoso (2014). Pengaruh Budaya, Sub Budaya, Kelas Sosial, dan Persepsi Kualitas Terhadap Perilaku Keputusan Pembelian Kue Tradisional Oleh Mahasiswa Surabaya. Jurnal Hospitality dan Manajemen Jasa.

Kurniawan, Ade Dharma; Rivai, Abdul; \& Suharto. (2018). Influence of Career Development and Motivation To Employee Performance Through Organizational Commitment in Institutional Development Section of Educational Diniyah and Pondok Pesantren Office of Ministry of South Jakarta,Vol 4, Issue 2, International Journal of Bussiness and Applied Social Science (IJBASS).

Samosir, Charlie Bernando Halomoan \& Arief Bowo Prayoga K. (2015). Pengaruh Perspsi Harga dan Promosi Terhadap Keputusan Pembelian Konsumen Produk Enervon C, Vol 1, No 3, Jurnal Ilmiah Manajemen dan Bisnis, Fakultas Ekonomi dan Bisnis Universitas Mercu Buana.

Saputra, Rico \& Hatane Semuel. (2013). Analisa Pengaruh Motivasi, Persepsi, Sikap Konsumen Terhadap Keputusan Pembelian Mobil Daihatsu Xenia di Sidoarjo, Jurnal Manajemen Pemasaran Vol 1 No 1, Universitas Kristen Petra.

Wahyuni, Urip. (2008). Analisa Pengaruh Motivasi, Persepsi, dan Sikap Konsumen Terhadap Keputusan Pembelian Sepeda Motor Merek 'Honda' di Kawasan Surabaya Jawa Barat, Jurnal Manajemen dan Kewirausahaan, Sekolah Tinggi Ilmu Ekonomi Fatahillah, Surabaya. 